\title{
Differences in functional traits of leaf blade and culm of common reed in four habitat types
}

\author{
Mun Gi Hong ${ }^{1}$, Bo Eun Nam ${ }^{1}$ and Jae Geun Kim ${ }^{1,2^{*}}$ (D
}

\begin{abstract}
We compared the functional traits of leaf blades and culms of common reed (Phragmites australis) in four habitat types of distinguished environments such as temperature, precipitation, water characteristics, and indices related to biomass production (montane fen, MF; riparian marsh, RM; lagoon, LG; and salt marsh, SM). We also examined the relationships between the functional traits within and among populations. Four populations showed remarkable differences in the functional traits of leaf blades and culms. MF and RM had relatively tall $(>300 \mathrm{~cm})$ and thick $(>8 \mathrm{~mm}$ ) culms bearing long leaf blades $(>40 \mathrm{~cm}$ ), whereas $L G$ and $S M$ had relatively shorter and thinner culms bearing shorter leaf blades than MF and RM. Some relationships between the functional traits of leaf blades and culms showed negative or not significant correlations within the population, whereas most of the relationships between the functional traits showed positive correlations particularly when all the data from four populations was included into the correlation analysis.
\end{abstract}

Keywords: Lagoon, Montane fen, Phragmites australis, Riparian marsh, Salt marsh

\section{Background}

Common reed (Phragmites australis [Cav.] Trin. ex Steud.) is one of the most widely distributed macrophytes on earth. $P$. australis has been observed throughout most continents such as Africa, America, Asia, and Europe (Engloner 2009; Hong and Kim 2011; Köbbing et al. 2013). In addition to the horizontal distribution, $P$. australis has also been reported to show vertically wide distribution from salt marshes to montane fens at extreme altitude (Hong and Kim 2011; Park et al. 2013; Nam et al. 2018a). Phragmites australis is not only one of the most-widely distributed but also one of the most productive macrophytes that could reach over $6 \mathrm{~m}$ in canopy height and $/$ or $4 \mathrm{~kg} / \mathrm{m}^{2}$ in standing crop production (Engloner 2009; Hong et al. 2014b). Phragmites australis of high productivity plays ecologically important roles in providing foods, resources, and shelters for various lives (Köbbing et al. 2013).

\footnotetext{
* Correspondence: jaegkim@snu.ac.kr
${ }^{1}$ Department of Biology Education, Seoul National University, Seoul 08826,

* Correspondence: jaegkim@snu.ac.kr
${ }^{1}$ Department of Biology Education, Seoul National University, Seoul 08826, Republic of Korea

${ }^{2}$ Center for Education Research, Seoul National University, Seoul 08826, Republic of Korea
}

As similar in other countries, $P$. australis functions with various ways in wetland ecosystems of Korea (Asaeda and Karunaratne 2006; Köbbing et al. 2013; Hong et al. 2018; Nam et al. 2018b). As well as natural wetlands of various types, $P$. australis mainly constitutes the vegetational components of artificial wetlands for water purification and ground stabilization because of high productivity and environmental tolerances (Hong et al. 2014b; Nam et al. 2018b). Phragmites australis of high buoyancy and salt tolerance plays a critical role as the major component of floating marshes and salt marshes in Korea (Hong et al. 2018; Nam et al. 2018a). In particular, it has been reported that floating mats composed mainly by $P$. australis could stably provide habitats for diverse endangered species (Kim et al. 2013; Hong et al. 2018).

Different morphology and/or population structure of a species could determine functions differently, and such different functions, in turn, affect services and value of ecosystems (Hong et al. 2018; Park et al. 2018). Thus, studies on the differences in morphology and/or population structure are of importance in understanding ecological roles of a certain species particularly in various 
habitat types. In that context, a number of studies on the functional traits of $P$. australis have been performed in Korea. According to Lee and Yang (1993), P. australis grew differently depending on the level of salinity. Hong and Kim (2011) also reported that P. australis could show different functional traits depending on the habitat type. Hong et al. (2018) noted that P. australis could inhabit in oligotrophic water conditions. Although numerous studies have been conducted to understand the functional traits of $P$. australis in Korea, most of the previous studies mainly focused on quantitative indices related to productivity such as shoot height, density, and biomass production in relations to environmental gradients and differences (Lee and Yang 1993; Hong and Kim 2011; Hong et al. 2014a, 2018). On the other hand, the study on the functional traits of blade and culm of $P$. australis is lacking yet.

Even though leaf blade and culm constitute the standing crop of $P$. australis together, those two components could differently contribute to the productivity including litter. Those two components are known to differently affect the decomposition process of organic matters due to different lignin contents (van Ryckegem et al. 2006). In addition to the chemical difference, it has also been reported that standing dead culms remain a couple of years, whereas leaf blades easily fall off and decompose rapidly, indicating different contributions to the process of litter decomposition (Gessner 2000). To understand production, decomposition, and nutrient dynamics in $P$. australis-dominated wetland ecosystems in detail, we need to take the approach that considers those two components separately.

Thus, in the present study, we tried to focus on the functional traits of the leaf blade and culm of $P$. australis. To examine differences in the functional traits of leaf blade and culm, we chose four habitats of distinguished environmental conditions such as temperature, precipitation, water characteristics, and indices related to biomass productions. We compared the differences in the functional traits of leaf blades and culms of four $P$. australis populations and also examined the relationships between the functional traits of leaf blades (length and number/culm) and culms (height and diameter) of within and among populations.

\section{Methods}

Four types of $P$. australis-dominated wetlands were selected as sampling sites (Additional file 1: Figure S1): montane fen (hereafter MF; $37^{\circ} 50^{\prime} 31^{\prime \prime} \mathrm{N}, 128^{\circ} 33^{\prime} 12^{\prime \prime}$ E), riparian marsh (RM; $37^{\circ} 27^{\prime} 59.4^{\prime \prime} \mathrm{N}, 127^{\circ} 18^{\prime} 11^{\prime \prime}$ E), lagoon (LG; $38^{\circ} 21^{\prime} 26^{\prime \prime} \mathrm{N}, 128^{\circ} 30^{\prime} 17^{\prime \prime} \mathrm{E}$ ), and salt marsh (SM; 34 50' $\left.16^{\prime \prime} \mathrm{N}, 127^{\circ} 27^{\prime} 00^{\prime \prime} \mathrm{E}\right)$. MF, RM, and LG are mat-based floating wetlands, whereas SM is a typical ground-based wetland. MF, RM, and LG are classified as non-tidal freshwater wetlands, whereas SM is as tidal saline-water wetlands. Study sites were totally different in terms of environmental conditions such as temperature, precipitation, water characteristics (electric conductivity, $\mathrm{pH}$, and cations), and indices related to biomass production of $P$. australis (Additional file 1: Figure S2 and Table S1). Culm (shoot) height and aboveground dry weight of four populations also showed clearly different levels among populations but not gradients (Additional file 1: Table S1). More detailed information on the sampling sites is available in Hong and Kim (2012) and Hong et al. (2018).

Field surveys were performed at the end of the growing season of each site. We sampled 60 shoots from each site except 48 shoots from montane fen with considering the conservative value of montane fen site, a Ramsar wetland (Park and Kim 2012). Inner areas of each wetland site mostly covered with $P$. australis were considered as sampling places. Unnaturally short shoots due to the status of broken or late growing were excluded in the field survey (Haslam 1969). Reed shoots bearing an inflorescence and fresh leaves were clipped at the level of the water surface in floating mats (MF, RM, and LG) and at the ground level in salt marsh site to measure the functional traits of leaf blades and culms. Culm height and blade length were measured using a measuring tape, and culm diameter was by vernier calipers. The length of inflorescence was included into the height of reed culm, whereas the length of leaf sheath was not included into the length of leaf blade. Culm diameter was measured at the bottom level of each culm (i.e., basal diameter, the thickest part of each culm).

Analysis of variance (ANOVA), Duncan's post hoc test, and correlation analysis for the functional traits of leaf blades and culms of four populations were performed by using statistical software, SPSS package for Windows (IBM SPSS Version 22.0, New York). Principal component analysis (PCA) for growth characteristics of leaf blade and culm was performed by $\mathrm{R}$ version 3.4.4 ( $\mathrm{R}$ Core Team 2018) with the "vegan" package.

\section{Results and discussion}

\section{Differences in functional traits of leaf blade and culm}

Four $P$. australis populations were clearly divided based on the functional traits of leaf blades (length and number/culm) and culms (length and diameter) by the PCA analysis (Fig. 1). In addition, four populations were also clearly divided into statistically different subgroups by Duncan's post hoc test $(p<.05)$ based on their culm height and blade length (Fig. 2a, d). The highest values in culm height $(354.5 \pm 24.0 \mathrm{~cm})$ and blade length $(50.2$ $\pm 3.6 \mathrm{~cm}$ ) were obtained in MF and were followed by, in order, RM $(284.3 \pm 37.1 \mathrm{~cm}$ in culm height and $43.7 \pm$ $4.6 \mathrm{~cm}$ in blade length), SM (194.3 $\pm 37.1 \mathrm{~cm}$ in culm 


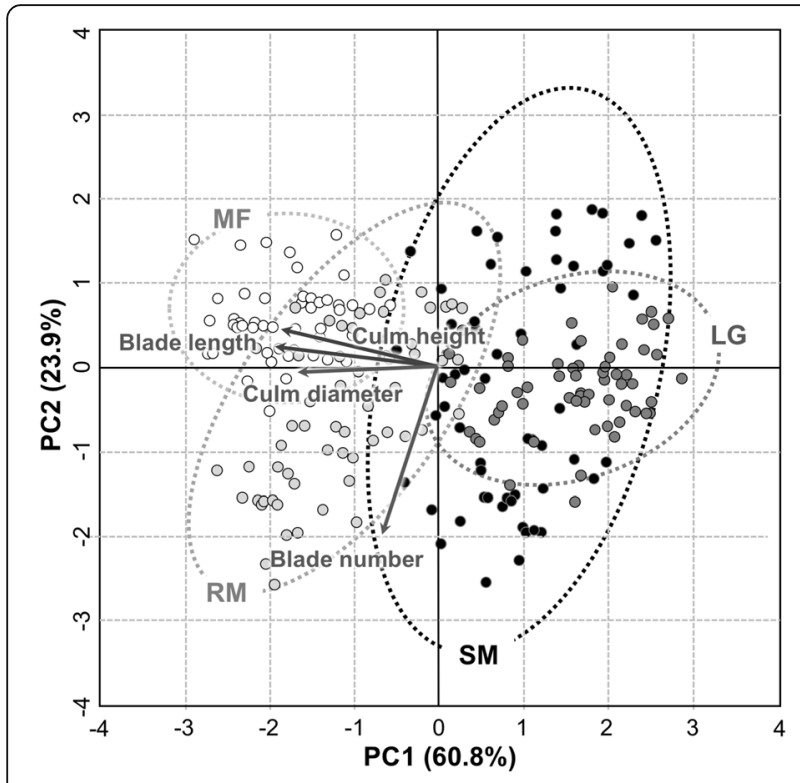

Fig. 1 The PCA result based on the functional traits of leaf blade and culm of $P$. australis populations from four habitat types. Dotted ellipses indicate the $95 \%$ range of standard deviation of each population. MF, montane fen $(n=48) ; \mathrm{RM}$, riparian marsh $(n=60) ; \mathrm{LG}$, lagoon $(n=60)$; $\mathrm{SM}$, salt marsh $(n=60)$

height and $31.1 \pm 4.6 \mathrm{~cm}$ in blade length), and LG (165.6 $\pm 29.1 \mathrm{~cm}$ in culm height and $22.8 \pm 4.2 \mathrm{~cm}$ in blade length). In the case of culm diameter, four populations were statistically divided into two groups (Fig. 2b). MF $(9.6 \pm 1.3 \mathrm{~mm})$ and $\mathrm{RM}(9.5 \pm 1.4 \mathrm{~mm})$ showed relatively higher values than LG $(7.5 \pm 1.3 \mathrm{~mm})$ and $\mathrm{SM}(7.5 \pm 1.4$ $\mathrm{mm})$. In addition to the culm diameter, in the case of the number of blade per culm, four populations were also statistically divided into two groups ( $p<.05$; Fig. 2 c).
RM (11.2 \pm 3.2 blades per culm) showed a relatively higher value than the others (MF, $8.7 \pm 1.4$ blades per culm; LG, $8.6 \pm 1.6$ blades per culm; SM, $9.2 \pm 3.2$ blades per culm).

Based on the results from the previous studies and the present study on the study sites (Hong and Kim 2012; Hong et al. 2018), it might be said that four populations of different habitat types are markedly different in terms of inhabiting environmental conditions and functional traits including the morphology of leaf blades and culms. According to the previous studies, $P$. australis populations in different environments and/or habitat types often show distinguished characteristics in terms of morphology and growth performance (Engloner 2009; Hong and Kim 2011). Varying morphology and growth performance of $P$. australis from different environments (or habitat types) might be the results of local adaptation, probably indicating the ecotypic characteristics of $P$. australis as a highly adaptive species in wetland ecosystems (Hanganu et al. 1999; Hong and Kim 2013).

\section{Relationships between functional traits of leaf blade and culm}

Four reed populations showed different patterns of the relationships between the functional traits of the leaf blade and culm (Additional file 1: Table S2). MF showed only a significant relationship between the height and diameter of culms (Pearson's $r=0.622, R^{2}=0.3869$, $p<.001)$. On the other hand, RM, LG, and SM showed three, five, and four significant relationships, respectively. MF, RM, and LG showed positive correlations only, whereas SM showed two positive and two negative correlations (culm height-culm diameter, $r=-0.317$,
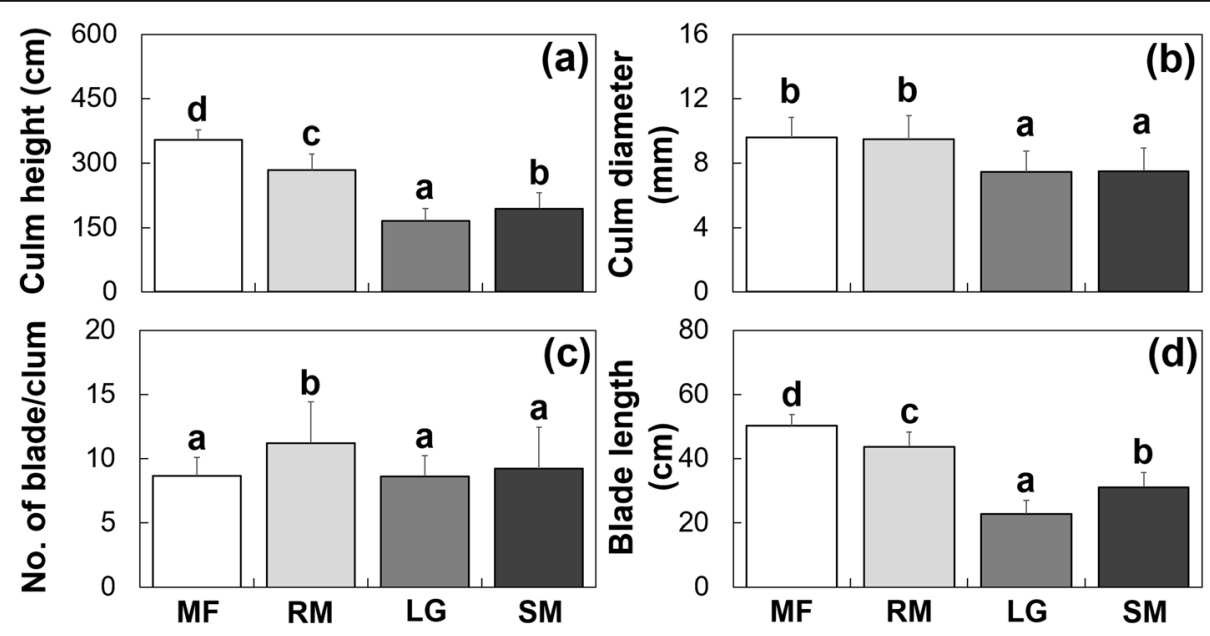

Fig. 2 Differences in the functional traits of leaf blade and culm of $P$. australis populations from four habitat types (mean \pm 1 SD). a Culm height. b Culm diameter. c Number of blade per culm. d Blade length. MF, montane fen (culm $n=48$, blade $n=415$ ); RM, riparian marsh (culm $n=60$, blade $n=672$ ); $L G$, lagoon (culm $n=60$, blade $n=517$ ); SM, salt marsh (culm $n=60$, blade $n=550$ ). Different alphabets indicate statistically different subgroups by Duncan's post hoc test $(p<.05)$ 
$R^{2}=0.1005, p<.05$; culm height-blade number, $r=-$ $0.679, R^{2}=0.4610, p<.001$ ).

Regardless of different patterns on the relationships within populations, most of the relationships between the functional traits (only except for the relationship between culm height and blade number) showed statistically significant correlations when all the data from four populations was included into the correlation analysis (Additional file 1: Table S2). The relationship between culm height and blade number derived from RM showed a high value $\left(R^{2}=0.6740\right.$, $p<.001$ ), whereas the relationship derived from whole sites showed not significant correlation (Fig. 3). On the other hand, in the relationships between culm height and blade length, only RM and LG showed significant values (RM, $R^{2}=0.1781, p<.001 ; \mathrm{LG}$, $\left.R^{2}=0.3931, p<.001\right)$, whereas the relationship derived from whole sites showed a markedly high value $\left(R^{2}=0.7310, p<.001\right)$.

Although most of the relationships showed statistically significant correlations when all the data from four populations was included into the correlation analysis (Fig. 3), the relationships including the number of blade showed significant but relatively lower values (culm diameter-blade number, $R^{2}=0.0471, p<.01$; blade number-blade length, $R^{2}=0.0396, p<.01$ ) or not

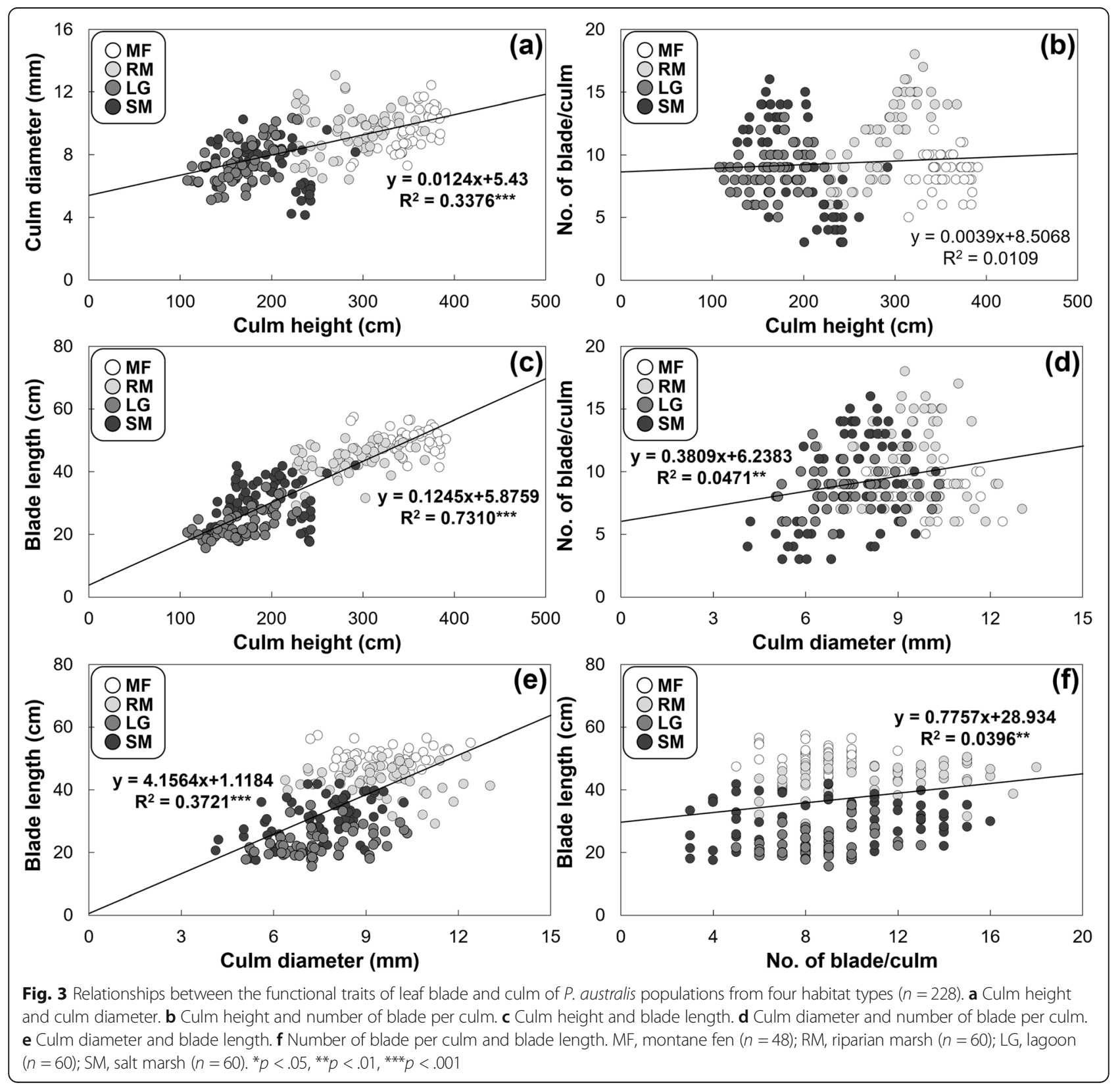


significant correlation (culm height-blade number) (Fig. 3). In contrast, the relationships between the functional traits of blade and culm except blade number showed strongly positive correlations (Additional file 1: Table S2).

Many studies have focused on the relationships between indices closely related to productivity such as culm height, density, and aboveground dry weight (AGDW) and morphological indices of $P$. australis such as culm diameter and leaf blade length (Haslam 1969; Engloner 2009; Hong and Kim 2011). Although a great number of studies have been conducted to understand the relationships between the functional traits of $P$. australis, the consensus on the relationships has not been obtained clearly. Some studies have found positive relationships between the functional traits such as the height and diameter of culm, and the density of culms and AGDW (Haslam 1969; Hong and Kim 2011). On the contrary, some other studies have found negative relationships (Mook and van der Toorn 1982; Ritterbusch 2007) or even not significant relationships at all (Coops and van der Velde 1996).

As similar with the previous studies, in the present study, four $P$. australis populations showed different relationships between functional traits depending on not only the kind of functional trait but also the type of habitat. Some relationships between the functional traits showed negative or not significant correlations within populations, whereas most of the relationships between the functional traits showed positive correlations particularly when all the data from four populations was included into the correlation analysis (Haslam 1969; Hong and Kim 2011). In particular, unlike other P. australis populations in freshwater marshes (MF, RM, and LG), negative correlations between functional traits were obtained only from the population in salt marsh (SM). It might be the result of local adaptation because of distinguished environments between freshwater and salt marshes (Hanganu et al. 1999). In order to deeply understand the functional traits of $P$. australis and the relationships between those traits in detail, further studies with focusing on the effects of genetic and environmental differences on the functional traits of $P$. australis are needed.

\section{Additional file}

Additional file 1: Figure S1. The location of the study sites. MF = montane fen, $\mathrm{RM}=$ riparian marsh, $\mathrm{LG}=$ lagoon, $\mathrm{SM}=$ salt marsh. Figure $\mathbf{S 2}$. Mean temperature and precipitation (mean $\pm 1 \mathrm{SE}$ ) in the study sites from 2012 to 2018. MF = montane fen, $\mathrm{RM}=$ riparian marsh, $\mathrm{LG}=$ lagoon, $\mathrm{SM}=$ salt marsh. Table S1. Water characteristics and plant functional traits of the study sites from the previous studies (mean \pm 1 SD). Table S2. The result from the correlation analysis (Pearson's $r$ ) on the functional traits of the leaf blade and culm of four P. australis populations. (DOCX $219 \mathrm{~kb}$ )

\section{Abbreviations}

AGDW: Aboveground dry weight; LG: Lagoon; MF: Montane fen; RM: Riparian marsh; SM: Salt marsh

\section{Acknowledgements}

Not applicable.

\section{Funding}

This research was supported by the National Research Foundation of Korea (NRF) funded by the Ministry of Education (NRF-2015R1D1A1A01057373) and by the Korea government (MSIT) (NRF-2018R1A2B2002267).

\section{Availability of data and materials}

The datasets during and/or analyzed during the current study are available from the corresponding author on reasonable request.

\section{Author's contributions}

MGH participated in the design of the study, field sampling, data analyses and wrote the manuscript draft. BEN participated in the field survey and data analyses and edited the manuscript draft. JGK conceived the study, participated in the design of the study, edited the manuscript draft, and secured the funding. All authors read and approved the final manuscript.

Ethics approval and consent to participate

Not applicable.

Consent for publication

Not applicable.

Competing interests

The authors declare that they have no competing interests.

\section{Publisher's Note}

Springer Nature remains neutral with regard to jurisdictional claims in published maps and institutional affiliations.

Received: 2 March 2019 Accepted: 27 March 2019

Published online: 08 April 2019

\section{References}

Asaeda T, Karunaratne S. Dynamic modeling of the growth of Phragmites australis: model description. Aquat Bot. 2006;7(4):301-18.

Coops H, van der Velde G. Effects of waves on helophyte stands: mechanical characteristics of stems of Phragmites australis and Scirpus lacustris. Aquat Bot. 1996:53:175-85.

Engloner Al. Structure, growth dynamics and biomass of reed (Phragmites australis)-a review. Flora. 2009;204:331-46.

Gessener MO. Breakdown and nutrient dynamics of submerged Phragmites shoots in the littoral zone of a temperate hardwater lake. Aquat Bot. 2000; 66(1):9-20

Hanganu J, Mihail G, Coops H. Responses of ecotypes of Phragmites australis to increased seawater influence: a field study in the Danube Delta, Romania. Aquat Bot. 1999;64(3-4):351-8.

Haslam SM. The development of the annual population in Phragmites communis Trin. Ann Bot. 1969;34:571-91.

Hong MG, Heo YJ, Kim JG. The construction and management of artificial wetland using emergent macrophytes for high biomass production. J Wetl Res. 2014a;16(1):61-72.

Hong MG, Kim JG. Growth characteristics of cutting culms sectioned at different positions from three reed populations. J Korean Soc Environ Restor Techno. 2012;15(1):53-62.

Hong MG, Kim JG. Cutting efficiency using Phragmites australis culms according to content and timing of indole-acetic acid treatment. J Wetl Res. 2013;15(1): 35-41.

Hong M-G, Kim JG. Comparative analysis of cutting efficiency using culms of reed with genetic, environmental and methodological differences. J Korean Wetl Soc. 2011;13(3):603-11.

Hong MG, Nam BE, Kim JG. Vegetation and water characteristics of floating mat in a coastal lagoon as the habitat for endangered plant species. J Ecol Environ. 2018;42:28. 
Hong MG, Son CY, Kim JG. Effects of interspecific competition on the growth and competitiveness of five emergent macrophytes in a constructed lentic wetland. Paddy Water Environ. 2014b;12(Supp.1):S193-202.

Kim HT, Lee GM, Kim JG. The ecological characteristics and conservation counterplan of Menyanthes trifoliata habitat in floating mat in Korean east coastal lagoon, Sunyoodam. J Wetl Res. 2013;15(1):25-34.

Köbbing JF, Thevs N, Zerbe S. The utilisation of reed (Phragmites australis): a review. Mires Peat. 2013;13(1):1-14.

Lee H-J, Yang H-S. Adaptation of Phragmites communis Trin. Population to soil salt contents of habitats. Korean J Ecol. 1993;16(1):63-74.

Mook JH, van der Toorn J. The influence of environmental factors and management on stands of Phragmites australis. II. Effects on yield and its relationships with shoot density. J Appl Ecol. 1982;19(2):501-17.

Nam BE, Hong MG, Park HJ, Kim JG. Soil factors determining the distribution of Phragmites australis and Phacelurus latifolius in upper tidal zone. J Ecol Environ. 2018a;42:25.

Nam BE, Kim JG, Hong MG. Vegetation and water characteristics of an ecotechnological water purifying biotope in Yongin. J Wetl Res. 2018b;20(4):432-45.

Park HJ, Nam BE, Hong MG, Kim JG. Slope and soil nutrients can explain the distribution of Phragmites australis and Phragmites japonica in riparian wetlands. River Res Applic. 2018;34(9):1229-33.

Park J, Hong MG, Kim JG. Relationship between early development of plant community and environmental condition in abandoned paddy terraces at mountainous valleys in Korea. J Ecol Environ. 2013;36(2):131-40.

Park JH, Kim JG. Ecological characteristics of Sphagnum fens in Mt. Odae: 2. Conservation area of Jilmoe-neup. J Wetl Res. 2012;14(1):101-20.

$R$ Core Team. R: a language and environment for statistical computing. Vienna: $R$ Foundation for Statistical Computing; 2018

Ritterbusch D. Growth patterns of reed (Phragmites australis): the development of reed stands in carp ponds. Aquacult Int. 2007;15:191-9.

van Ryckegem G, van Driessche G, van Beecumen JJ, Verbeken A. The estimated impact of fungi on nutrient dynamics during decomposition of Phragmites australis leaf sheaths and stems. Microb Ecol. 2006:52:564-74.

Ready to submit your research? Choose BMC and benefit from:

- fast, convenient online submission

- thorough peer review by experienced researchers in your field

- rapid publication on acceptance

- support for research data, including large and complex data types

- gold Open Access which fosters wider collaboration and increased citations

- maximum visibility for your research: over $100 \mathrm{M}$ website views per year

At $\mathrm{BMC}$, research is always in progress.

Learn more biomedcentral.com/submissions 